\title{
Vanet heterogeneous networks with wireless technology variation according to the capacity of users in urban areas
}

Autores

Amelec Viloria, Omar Bonerge Píneda Lezama, Noel Varela

\begin{abstract}
As of late, traffic blockage, street mishaps, and ecological contamination brought about by traffic, alongside the need to associate and utilize constant applications, have become issues of worldwide intrigue. Different on-screen characters, for example, vehicle producers, the scholarly community, and government offices have begun to invest a ton of energy together towards the acknowledgment of the idea of huge scope vehicular interchanges. One of the primary methodologies in this kind of system is the advancement of remote advances and their assorted organizations, concentrating on the association with the Internet through WiFi systems, cell systems, or specially appointed vehicular systems. VANETs are essentially intended to give data trade through Vehicle to Vehicle (V2V) and Vehicle to foundation (V2I) interchanges, permitting ceaseless network and being exceptionally utilized for short-range correspondence, with high transmission speed through which it is proposed that clients keep up an association and distinguish occasions about clog or street conditions. This exploration presents a vehicular situation that tries to acquire a sufficient presentation while executing a heterogeneous network in a few segments of the city of Bogotá, Colombia.
\end{abstract}

Palabras clave

Coverage, heterogeneous, throughput, VANET, WIFI, DSRC 